\title{
AEROMAGNETIC MAP OF THE KENT QUADRANGLE, LITCHFIELD AND FAIRFIELD COUNNTIES, CONNECTICUT
}

\author{
GEOPHYSICAL INVESTIGATIONS \\ MAP GP-816
}

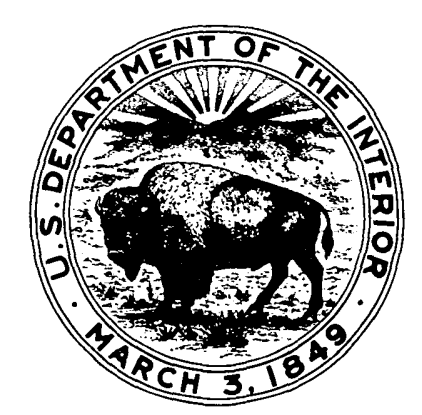

PUBLISHED BY THE U.S. GEOLOGICAL SURVEY 